\title{
Power-dependent physical properties of GaN thin films deposited on sapphire substrates by RF magnetron sputtering
}

\author{
ASİM MANTARCI ${ }^{1, *}$ (i) and MUTLU KUNDAKÇI ${ }^{2}$ \\ ${ }^{1}$ Department of Physics, Faculty of Art and Science, Muş Alparslan University, Muş 49250, Turkey \\ ${ }^{2}$ Department of Physics, Faculty of Science, Atatürk University, Erzurum 25250, Turkey \\ *Author for correspondence (a.mantarci@alparslan.edu.tr; asimmantarci@gmail.com)
}

MS received 30 October 2018; accepted 4 March 2019

\begin{abstract}
Gallium nitride ( $\mathrm{GaN}$ ) thin films were grown on the $\mathrm{Al}_{2} \mathrm{O}_{3}(0001)$ substrate using radio frequency (RF) magnetron sputtering under various RF powers. Many experimental techniques were used for investigating the effects of RF power on the GaN thin film growth and its physical properties. The X-ray diffraction results confirmed that the GaN thin film had a polycrystalline structure with planes of (101) and (202). The structural parameters of the thin film changed with RF powers. It was also found that the optical band gap energy of GaN thin films varied with changing RF power. From the atomic force microscopy images, almost homogeneous, nanostructured and a low-rough surface of the GaN thin film can be observed. From scanning electron microscopy analysis, dislocations and agglomerations were observed in some regions of the surface of the GaN thin film. $E_{2}$ (high) optical phonon mode of $\mathrm{GaN}$ was observed, proving the hexagonal structure of the thin film. The residual stress in the GaN thin films was calculated from Raman measurements. Furthermore, an agreement between the experimental measurements was also examined. The morphological, structural and optical properties of the $\mathrm{GaN}$ thin film could be improved with altering RF power. These films could be used in devices such as light emitting diodes, solar cells and diode applications.
\end{abstract}

Keywords. GaN; III-nitride; radio frequency; sapphire; RF magnetron sputtering.

\section{Introduction}

III-Nitride semiconductors (direct-wide band gap $\sim 1.95-$ $6.2 \mathrm{eV}$ ) play an important role in optoelectronic applications [1-3]. Recently, many distinguished scientists have explored such materials deeply for use in high technology [4-12]. One of them, gallium nitride $(\mathrm{GaN})$ has significant properties including direct wide band gap $(\sim 3.4 \mathrm{eV})$, thermal stability, high-melting point [13], high-electron mobility [14], mechanical hardness and high-breakdown voltage [15]. Due to these properties, this material has become one of the core materials of industrial devices. These devices can be a high-power transistor [16,17], optical device with a short wavelength [18], photo-detector [19], light emitting diode (LED) device [20-22], solar cell [23,24], pH sensor [25] and betavoltaic device [26]. Many thin film deposition techniques can be used to grow high-quality GaN thin films including pulsed laser deposition [27], metal-organic chemical vapour deposition [28], atomic layer deposition [29], molecular beam epitaxy (MBE) [30], thermionic vacuum arc [31,32], sputtering [33] and sol-gel [34]. Radio frequency (RF) magnetron sputtering has emerged as a useful method for producing high-quality GaN thin films at lower temperature [35]. Several studies on GaN thin films using RF sputtering have been published. Li et al [36] reported that $\mathrm{p}-\mathrm{CuS} / \mathrm{n}-\mathrm{GaN}$ heterojunctions were produced using $\mathrm{RF}$ magnetron sputtering. The crystal structure of the film was improved by changing the annealing temperature. Also, the diode parameters showed good behaviour in rectification and low leakage. The turn-on voltage of the diode was $1.2 \mathrm{~V}$. They concluded that the optical band gap energies of the material can be altered by the annealing temperature. $\mathrm{Wu}$ et al [37] studied that nanorods of GaN were produced on a $\mathrm{Si}$ (111) substrate using RF magnetron sputtering. The structure of nanorods shows GaN with a single crystal hexagonal wurtzite and their diameters were from 100 to $400 \mathrm{~nm}$. They found that at room temperature the PL spectrum exhibits a strong emission at $369 \mathrm{~nm}$ and a relatively weak emission at $403 \mathrm{~nm}$. Kuo et al [38] studied the role of Mg doping in the physical properties of the thin film using RF magnetron sputtering. As a result, they successfully produced $\mathrm{P}-\mathrm{N}$ diodes that are environmentally friendly. Li et al [39] produced n-ZnO:Al (AZO)/i-layer/n-GaN heterojunctions using RF magnetron sputtering. They analysed ultraviolet electroluminescence (UV-EL) of heterojunctions at room temperature. A strong UV peak at $\sim 370 \mathrm{~nm}$ was detected for $\mathrm{AZO} / \mathrm{i}$ $\mathrm{ZnO} / \mathrm{n}-\mathrm{GaN}$ and $\mathrm{AZO} / \mathrm{i}-\mathrm{MgO} / \mathrm{n}-\mathrm{GaN}$ heterojunctions. They deeply discussed the emission mechanism in the produced devices using EL spectra. In another study, Abud et al [40] researched that the GaN thin film was deposited on a flat and porous silicon substrate using the RF sputtering method. The $\mathrm{X}$-ray diffraction (XRD) results proved that the GaN thin 
film has a hexagonal structure. Photoluminescence (PL) spectroscopy was conducted to obtain the optical parameters of the films, resulting in good optical properties. Yudate et al [41] researched that Eu-doped $\mathrm{GaN}(\mathrm{GaN}: \mathrm{Eu})$ films were produced on $c-\mathrm{Al}_{2} \mathrm{O}_{3}, \mathrm{GaAs}(100)$ and $\mathrm{Si}$ (100) substrates using a RF magnetron sputtering technique. They reached the conclusion that the lattice constant of the material decreased with the annealing temperature. Kusaka et al [42] reported that the GaN thin film was grown using the RF magnetron sputtering technique from the GaN powder target. They analysed the residual stress in the thin films and the crystal orientation of thin films in detail. The thin films had a good crystal orientation along the $c$-axis normal to the substrate. The tensile stress in the GaN thin film was obtained at nitrogen concentration $\leq 20 \%$ whereas the compressive residual stress in the GaN thin film was obtained at nitrogen concentration $\geq 50 \%$. Shinoda et al [43] investigated that $\mathrm{GaN}$ and alloys (InGaN and AlGaN) were produced on an $\mathrm{Al}_{2} \mathrm{O}_{3}$ substrate using the RF magnetron sputtering technique. The physical properties of the material were analysed depending on some growth parameters (substrate temperature and gas pressure). The gallium $(\mathrm{Ga})$ rich growth material displayed a flat surface and the nitrogen $(\mathrm{N})$ rich growth material displayed a pyramid type structure. In the reported studies, no study about the impacts of RF power on the physical properties of the $\mathrm{GaN} / \mathrm{Al}_{2} \mathrm{O}_{3}$ thin film by $\mathrm{RF}$ magnetron sputtering has been found. Therefore, we think that the study of this subject has been important in terms of fulfilling scientific curiosity and contributing some to the literature. In this study, the RF power dependency on the physical properties of the $\mathrm{GaN} / \mathrm{Al}_{2} \mathrm{O}_{3}$ thin film using $\mathrm{RF}$ magnetron sputtering was researched. Two aspects of our work can be considered as a novelty. Although numerous studies on the growth of $\mathrm{GaN}$ thin films were found in the literature as mentioned above, the change in the RF power effect on the $\mathrm{GaN} / \mathrm{Al}_{2} \mathrm{O}_{3}$ thin film growth has not been studied. Another factor has been the RF sputtering technique, which we use to grow GaN thin films. This technique is cheaper compared to other known techniques (e.g., MBE) and thin films can be produced in a shorter time. By using this technique, better applications for polycrystalline films can be obtained such as producing polycrystalline CdTe thin film solar cells reported in the literature [44]. Scanning electron microscopy (SEM) and atomic force microscopy (AFM) were conducted to understand the RF power effects on the surface morphology of thin films.
XRD measurement was conducted for structural analysis of the material. Raman measurement was used to study the residual stress in the thin film and to analyse the optical phonon modes of the thin film. The optical measurements were conducted to obtain the optical band gap energies of the thin film.

\section{Experimental}

RF magnetron sputtering with a PVD-Midas 3M model (System number: VK-1601-2) was used for GaN thin film growth at DAYTAM (Centre of East Anatolian High-Technology Research and Application). The technical specifications of our system can be listed as follows: substrate rotation is 3-30 rpm, ultimate vacuum pressure is $\leq 5 \times 10^{-8}$ Torr, maximum substrate heating is $800^{\circ} \mathrm{C}$, substrate size is about 4-8 in. diameter, and the control is provided as fully automatic. A turbomolecular pump and a mechanical pump integrated into our system were operated to remove defects (oxygen and other gases). We purchased a GaN target with $99.99 \%(4 \mathrm{~N})$ purity and with 2 in.dia $\times 0.125$ in. thick from ACI Alloys, Inc. with lot no: 22709-16-02. Sapphire $\left(\mathrm{Al}_{2} \mathrm{O}_{3}\right.$ (0001)- $c$ plane) was purchased as a substrate from Sigma-Aldrich Chemistry Company. $\mathrm{Al}_{2} \mathrm{O}_{3}$ substrates were cleaned by applying Radio Corporation of America-1 (RCA1) and Radio Corporation of America-2 (RCA-2) cleaning procedures [45] before thin films were grown. Also, all the substrates used were carefully cut into an appropriate size with a diamond cutter. Seventy five sccm argon gas and $3 \mathrm{sccm}$ nitrogen gas were used in the system as growing gases (sccm infers standard cubic centimetre per minute at standard temperature and pressure). During the growth period, the system was provided with 50,75, 100 and $125 \mathrm{~W} \mathrm{RF}$ power. ISO 7 class clean room at DAYTAM was used for all experimental processes. The growth conditions of the $\mathrm{GaN} /$ sapphire thin films for different RF powers are presented in table 1 . We measured the thickness of GaN thin films using a surface profile metrology P7 (KLA-Tencor). In addition to this, we measured the thickness of thin films using a RF magnetron sputter sensor. By comparing these values, the calibration of the RF magnetron sputter sensor value was achieved using a profile meter. Field emission scanning electron microscopy (FE-SEM), ultraviolet/visible/near infrared (UV/Vis/NIR) spectroscopy, XRD, micro-Raman

Table 1. Growth conditions of GaN/sapphire thin films for different RF powers.

\begin{tabular}{lcccccc}
\hline $\begin{array}{l}\text { RF power } \\
(\mathrm{W})\end{array}$ & $\begin{array}{c}\text { Base pressure } \\
(\mathrm{kPa})\end{array}$ & $\begin{array}{c}\text { Working pressure } \\
(\mathrm{kPa})\end{array}$ & $\begin{array}{c}\text { Film thickness } \\
(\mathrm{nm})\end{array}$ & $\begin{array}{c}\text { Growth time } \\
(\mathrm{min})\end{array}$ & $\begin{array}{c}\text { Growth rate } \\
\left(\AA \mathrm{A} \mathrm{s}^{-1}\right)\end{array}$ & $\begin{array}{c}\text { Substrate temperature } \\
\left({ }^{\circ} \mathrm{C}\right)\end{array}$ \\
\hline 50 & $0.21 \times 10^{-6}$ & $0.90 \times 10^{-3}$ & $112 \pm 3.3$ & 187 & 0.1 & 300 \\
75 & $0.19 \times 10^{-6}$ & $0.87 \times 10^{-3}$ & $114 \pm 3.4$ & 95 & 0.2 & 300 \\
100 & $0.85 \times 10^{-7}$ & $0.86 \times 10^{-3}$ & $111 \pm 3.3$ & 62 & 0.3 & 300 \\
125 & $0.25 \times 10^{-6}$ & $0.85 \times 10^{-3}$ & $115 \pm 3.4$ & 48 & 0.4 & 300 \\
\hline
\end{tabular}




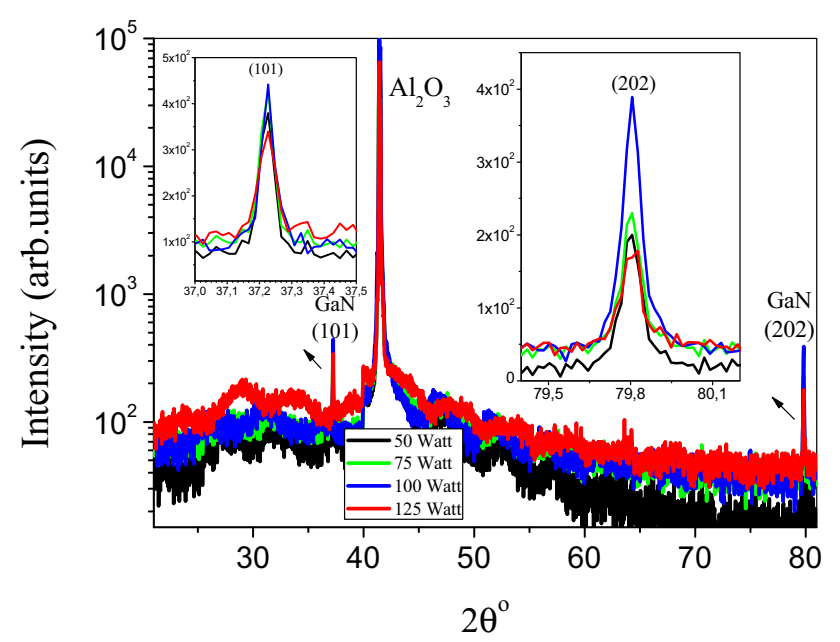

Figure 1. XRD Pattern of $\mathrm{GaN} / \mathrm{Al}_{2} \mathrm{O}_{3}$ thin films for different $\mathrm{RF}$ powers.

spectroscopy and AFM were conducted for the physical characterization of our material. The morphological analysis of the GaN thin film was studied using AFM-500II. A PANalytical XRD system with an Empyrean model was used $(\mathrm{CuK} \alpha=1.5406 \AA)$ to analyse the structure of $\mathrm{GaN}$ thin films. An alpha $300 \mathrm{R}$ micro-Raman spectrometer was used for the analysis of the optical phonon mode and residual stress. Using a model of LAMBDA $1050 \mathrm{UV} / \mathrm{Vis} / \mathrm{NIR}$ spectrophotometer, optical analysis of thin films was performed. A field-emission scanning electron microscope (FE-SEM), Zeiss Sigma 300 model, was used for morphological and surface analyses of the material. All measurements were performed at advanced spectroscopy laboratories at DAYTAM.

\section{Results and discussion}

\subsection{Structural analysis by XRD}

The XRD pattern of the $\mathrm{GaN} / \mathrm{Al}_{2} \mathrm{O}_{3}$ thin film under various RF powers is shown in figure 1. The XRD peak of $37.2^{\circ}$ was detected under $50,75,100$ and $125 \mathrm{~W}$ RF power growth conditions. It was originated from the (101) plane of hexagonal GaN by PDF code: 01-079-2499 from inorganic crystal structure database (ICSD). XRD peaks of $79.80,79.80,79.80$ and $79.82^{\circ}$ were observed under 50, 75, 100 and $125 \mathrm{~W}$ RF power growth conditions, respectively. They have originated from diffraction from the (202) plane of hexagonal GaN with PDF code: 01-074-0243 from ICSD. From the XRD results, it was found that the structure of the GaN thin film has been polycrystalline with (101) and (202) planes. It was seen that peaks of $\sim 38.06^{\circ}$ were shifted to $\sim 37.20^{\circ}$ for (101) planes of hexagonal $\mathrm{GaN}$ and peaks of $78.68^{\circ}$ were shifted to $79.80^{\circ}$ for (202) planes of hexagonal $\mathrm{GaN}$. It was interpreted that these shifts have originated from strains in the films. As another reason, the shift in the XRD peak could be due to non-stoichiometry. The Ga to $\mathrm{N}$ ratio
Table 2. Texture coefficient $\left(T_{\mathrm{c}}\right)$ of each plane for different RF powers.

\begin{tabular}{lccc}
\hline $\begin{array}{l}\text { Applied RF } \\
\text { power }(\mathrm{W})\end{array}$ & $(h k l)$ & $\begin{array}{c}\text { Measured } \\
\text { intensity }\left(I_{(\mathrm{hkl})}\right)^{*}\end{array}$ & $\begin{array}{c}\text { Texture } \\
\text { coefficient }\left(T_{\mathrm{c}}\right)\end{array}$ \\
\hline 50 & $(101)$ & 380 & 0.380 \\
& $(202)$ & 200 & 0.740 \\
75 & $(101)$ & 428 & 0.428 \\
& $(202)$ & 230 & 0.851 \\
100 & $(101)$ & 442 & 0.442 \\
& $(202)$ & 389 & 1.440 \\
125 & $(101)$ & 340 & 0.340 \\
& $(202)$ & 169 & 0.625 \\
\hline
\end{tabular}

*Relative intensities $\left(I_{0(\mathrm{hkl})}\right)$ for (101) and (202) are 1000 and 270, respectively.

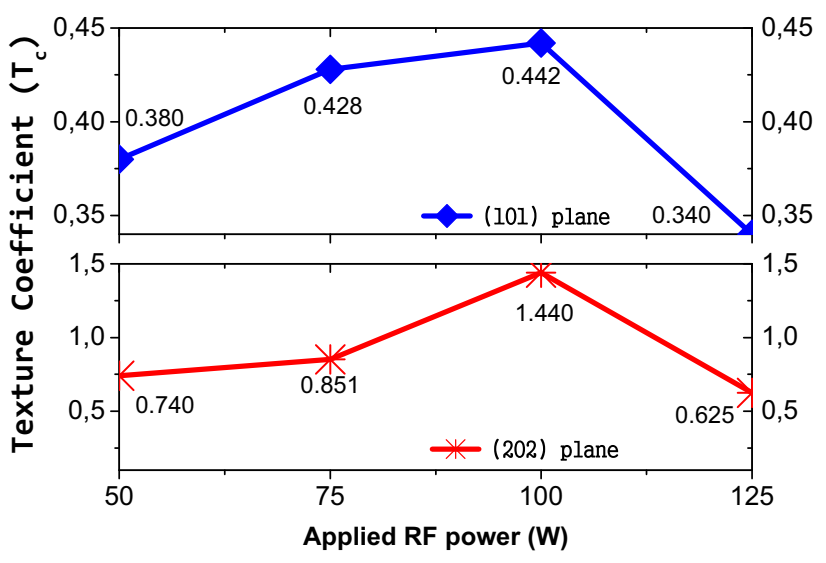

Figure 2. Texture coefficient values for different RF powers.

of the thin film was estimated to be $\mathrm{Ga}_{0.7175} \mathrm{~N}_{0.2825}$ using the Vegard law. A very sharp peak at $41.45^{\circ}$ belonging to sapphire was also detected as we expected, in agreement with the literature [46]. The crystallography texture coefficient $\left(T_{\mathrm{c}}\right)$ for each plane was calculated from XRD measurement results. Calculations were performed using the famous Harris texture formula:

$$
T_{\mathrm{c}(\mathrm{hkl})}=\frac{I_{(\mathrm{hkl})} / I_{0(\mathrm{hkl})}}{(1 / N)\left[\sum_{N}\left(I_{(\mathrm{hkl})} / I_{0(\mathrm{hkl})}\right)\right]}
$$

$T_{\mathrm{c}(\mathrm{hkl})}$ shows the texture coefficient for the $(h k l)$ plane, $I_{(\mathrm{hkl})}$ shows the intensity from XRD measurements, $I_{0(\mathrm{hkl})}$ shows the relative intensity for the $(h k l)$ plane from the corresponding PDF code and $N$ shows the number of reflections. The texture coefficient values for each plane are shown in table 2 . Increasing the power from 50 to $75 \mathrm{~W}$ results in an increase in the texture coefficient value for both planes. When the power is increased from 75 to $100 \mathrm{~W}$, the texture coefficient value is increased. When the power is increased from 100 to $125 \mathrm{~W}$, the texture coefficient value is decreased as shown in figure 2 . In summary, the highest texture coefficient value for both 
planes was found with the power of $100 \mathrm{~W}$, the lowest texture coefficient value for both planes was found with the power of $125 \mathrm{~W}$. This means that a large number of crystallites are oriented by their $(h k l)$ planes in the direction of the specific crystalline plane if the texture coefficient is bigger than 1 . If the texture coefficient is close to 1 , it leads to more random orientations. If the texture coefficient is between 0 and 1 , it shows a grain orientation fault toward the considered plane. The grain sizes of the thin film were calculated using Scherrer's relationship [47]:

$$
D=K \lambda / \beta \cos \theta
$$

$K=0.9$ is a constant, $\beta$ shows the full-width at half maximum (FWHM) intensity, $\lambda$ shows the X-ray wavelength and $\theta$ shows Bragg's diffraction angle. The average grain sizes $(D)$ of our films were calculated using the highest peak intensity. The structural parameters of the $\mathrm{GaN} / \mathrm{Al}_{2} \mathrm{O}_{3}$ thin films grown by RF magnetron sputtering for different RF powers are displayed in table 3 . Increasing the RF power from 50 to $75 \mathrm{~W}$ has led to an increase in the FWHM value and the grain size of the thin film has decreased. This has resulted in a slight deterioration in the crystal structure of the GaN thin film. On the other hand, increasing the RF power from 75 to $100 \mathrm{~W}$ has led to a decrease in the FWHM value and the grain size of the thin film has increased. This has resulted in an improvement in the crystal quality of the GaN thin film. Increasing the RF power from 100 to $125 \mathrm{~W}$ has led to an increase in the FWHM value and the grain size of the thin film has decreased. This has caused deterioration in the crystal structure of the GaN thin film. From the XRD results, the following interpretations can be made. Increasing the RF power from 75 to $100 \mathrm{~W}$ led to an improvement in the crystal structure of the GaN thin film. We expected this result and evaluated that due to this reason $\mathrm{GaN}$ molecules gain better mobility on the surface due to having more kinetic energy, leading to an improvement in the crystal structure of the thin film. When the RF power of $100 \mathrm{~W}$ was reached, the GaN thin film with the best crystal structure was obtained. It can be inferred that the optimal value for the growth of our thin film has been $100 \mathrm{~W}$ RF power. Increasing the RF power from 100 to $125 \mathrm{~W}$ caused deterioration in the crystal structure of the GaN thin film. The reason for this deterioration in the crystal could be analysed in the way that high-RF power will lead to an increase in the decomposition of GaN (increment in vacancies of gallium and nitrogen), which will result in the deterioration of the crystal quality [48]. As a contradiction to our result, it was found that an increased RF power from 100 to $120 \mathrm{~W}$ leads to an improvement in the crystal structure of the $\mathrm{ZnO}$ thin film in the literature study [49]. The best crystallization in the structure of the $\mathrm{GaN} / \mathrm{Al}_{2} \mathrm{O}_{3}$ thin film was achieved under $100 \mathrm{~W}$ RF power growth conditions. The worst crystallization in the structure of the $\mathrm{GaN} / \mathrm{Al}_{2} \mathrm{O}_{3}$ thin film was obtained under $125 \mathrm{~W}$ RF power growth conditions. Lattice parameters $c$ and $a$ of the thin films can be computed by using the Bragg formula [50] and equation (4):

$$
\begin{aligned}
d_{\mathrm{hkl}} & =\frac{\lambda}{\left(2 \sin \theta_{\mathrm{hkl}}\right)} \\
\frac{1}{d_{\mathrm{hkl}}^{2}} & =\frac{4}{3}\left(\frac{h^{2}+h \cdot k+k^{2}}{a^{2}}\right)+\frac{l^{2}}{c^{2}}
\end{aligned}
$$

$d$ stands for inter-planar spacing, $\lambda$ means wavelength of the $\mathrm{X}$-ray source, $h k l$ stands for miller indices, $\theta_{\mathrm{hkl}}$ means reflection angle from $h k l$ miller indices and $a$ and $c$ refer to lattice parameters for the hexagonal material. Lattice parameters are presented in table 3 . The strain in the GaN thin film for $a$ and $c$ lattice parameters can be obtained using equation (5) [51]:

$$
\varepsilon_{\mathrm{c}}=\frac{c-c_{0}}{c_{0}}, \quad \varepsilon_{\mathrm{a}}=\frac{a-a_{0}}{a_{0}}
$$

$\varepsilon_{\mathrm{c}}$ and $\varepsilon_{\mathrm{a}}$ represent strain in the $\mathrm{GaN}$ thin film for $c$ and $a$ lattice parameters, respectively. $c_{0}$ and $a_{0}$ represent lattice parameters of stress free GaN, being $c_{0}=0.5185 \mathrm{~nm}$ and $a_{0}=$ $0.3188 \mathrm{~nm}$ in the literature [52]. The strain in the lattice parameter $(c)$ of the GaN thin film for the (101) plane was found to be -0.0324 for all RF power. The strain in the lattice parameter $(c)$ of the $\mathrm{GaN}$ thin film for the (202) plane was found to be -0.0109 for 50,75 and $100 \mathrm{~W}$ of the RF power. For $125 \mathrm{~W}$, the strain in the lattice parameter $(c)$ of the GaN thin film for the (202) plane was found to be -0.0111 . The minus sign indicates that the lattice parameter values are decreasing, indicating the compressive stress. It was found that the strain in the lattice parameter $(a)$ of the $\mathrm{GaN}$ thin film for the (101) plane was determined to be -0.0366 for all RF power. It was found that the strain in the lattice parameter $(a)$ of the GaN thin film for the (202) plane was determined to be -0.0152 for 50,75 and $100 \mathrm{~W}$ of the RF power. For $125 \mathrm{~W}$, the strain in the lattice parameter $(a)$ of the GaN thin film for the (202) plane was determined to be -0.0154 . The in-plane stress $\left(\sigma_{\mathrm{a}}\right)$ of the GaN thin film can also be obtained using equations (6 and 7) [53]:

$$
\begin{aligned}
& \frac{\varepsilon_{\mathrm{c}}}{\varepsilon_{\mathrm{a}}}=-\frac{2 v}{(1-v)} \\
& \varepsilon_{\mathrm{c}}=-E^{-1} \sigma_{\mathrm{a}} 2 v
\end{aligned}
$$

$\varepsilon_{\mathrm{c}}$ and $\varepsilon_{\mathrm{a}}$ show strain in the GaN thin film for $c$ and $a$ lattice parameters, $v$ shows Poisson's ratio, $E$ (196 GPa) shows the Young's modulus of GaN (taken from [54]). It was obtained that the in-plane stress $\left(\sigma_{\mathrm{a}}\right)$ of the $\mathrm{GaN}$ thin film for the (202) orientation to be $1.8136 \mathrm{GPa}$ for 50,75 and $100 \mathrm{~W}$ RF power. For $125 \mathrm{~W}$, the attained in-plane stress $\left(\sigma_{\mathrm{a}}\right)$ of the $\mathrm{GaN}$ thin film for the (202) orientation was $1.9306 \mathrm{GPa}$. We obtained the in-plane stress $\left(\sigma_{\mathrm{a}}\right)$ of the GaN thin film for the (101) orientation to be $3.9984 \mathrm{GPa}$ for all applied RF power. On analysing the reason for the strain and stress in the $\mathrm{GaN}$ thin film, we have found that they may be attributed to the point 


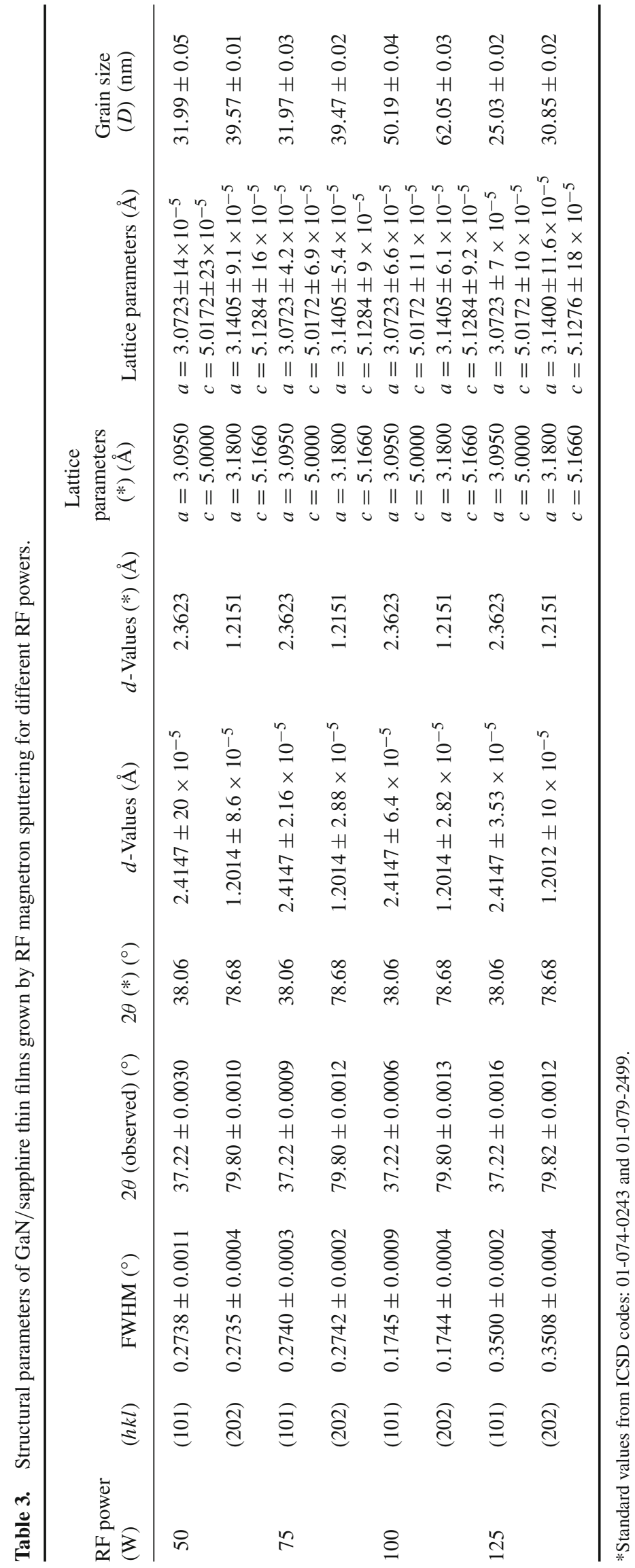




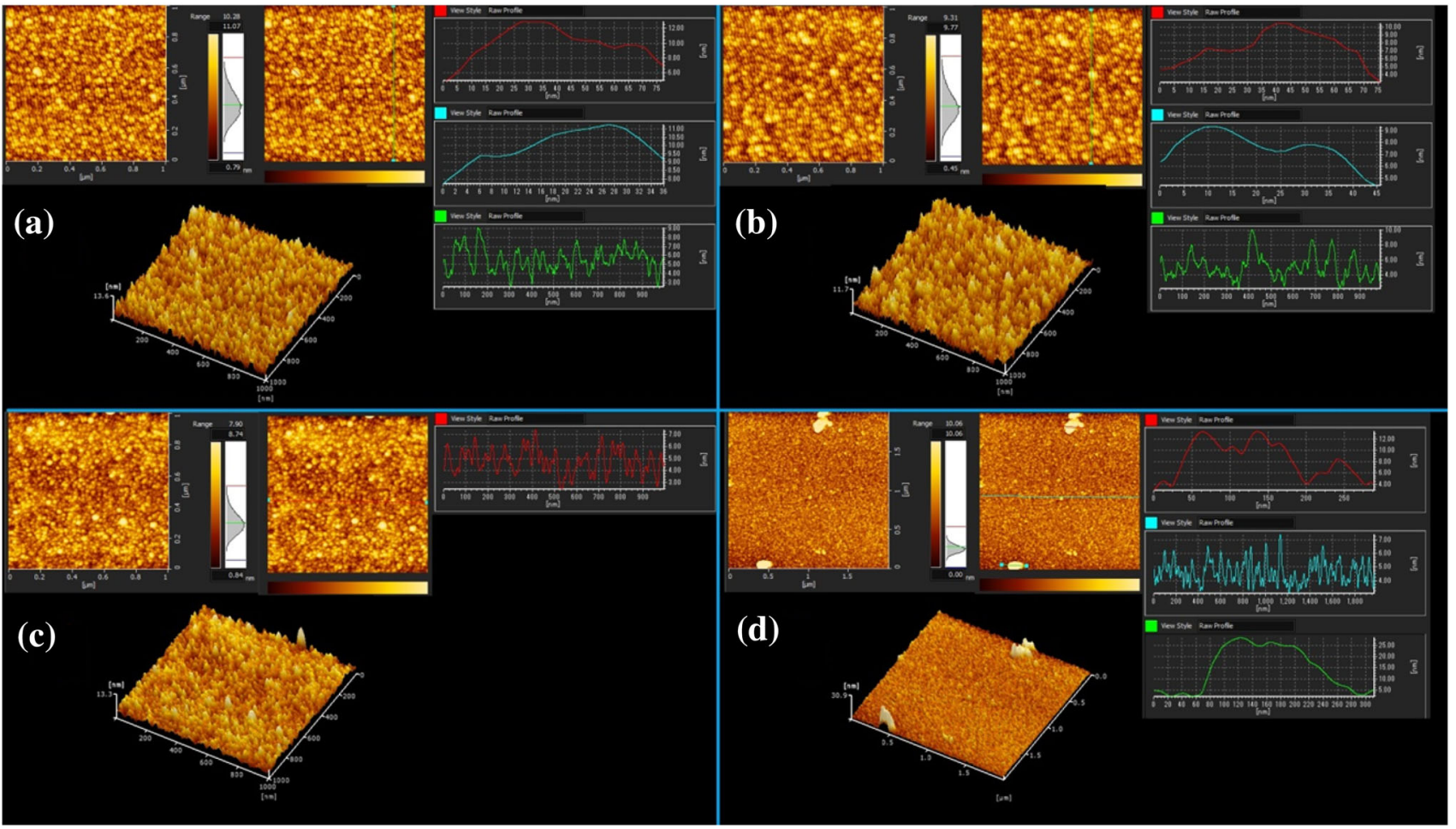

Figure 3. AFM image of $\mathrm{GaN} / \mathrm{Al}_{2} \mathrm{O}_{3}$ thin films for (a) 50, (b) 75 , (c) 100 and (d) $125 \mathrm{~W}$ RF powers.

Table 4. Morphological parameters of GaN/sapphire thin films for different RF powers.

\begin{tabular}{lccccc}
\hline $\begin{array}{l}\text { RF power } \\
(\mathrm{W})\end{array}$ & $\begin{array}{c}\text { Average roughness } \\
\left(R_{\mathrm{a}}\right)(\mathrm{nm})\end{array}$ & $\begin{array}{c}\text { Maximum peak } \\
\text { height }\left(R_{\mathrm{p}}\right)(\mathrm{nm})\end{array}$ & $\begin{array}{c}\text { Root mean square } \\
\text { roughness }\left(R_{\mathrm{q}}\right)(\mathrm{nm})\end{array}$ & $\begin{array}{c}\text { Average absolute } \\
\text { slope }(\Delta a)\left({ }^{\circ}\right)\end{array}$ & $\begin{array}{c}\text { Maximum valley } \\
\text { depth }\left(R_{\mathrm{v}}\right)(\mathrm{nm})\end{array}$ \\
\hline 50 & 0.46 & 1.38 & 0.55 & 1.76 & 1.55 \\
75 & 0.20 & 0.77 & 0.24 & 0.62 & 0.50 \\
100 & 0.78 & 2.53 & 0.96 & 6.01 & 2.31 \\
125 & 0.09 & 0.44 & 0.11 & 0.99 & 0.27 \\
\hline
\end{tabular}

defect (coming from surface plasma interactions) and also the oxygen impurity in the GaN thin film [55]. The XRD results of the GaN thin film are very important for the production of optoelectronic devices to determine the quality of the crystal we have obtained. The optimization of growth conditions has been necessary to be able to produce good crystals of $\mathrm{GaN} / \mathrm{Al}_{2} \mathrm{O}_{3}$. By altering the RF power values, we were able to improve the crystal structure to some extent. To obtain a high-quality GaN thin film, other growth conditions can also be optimized. Although our system has been vacuumed at a sufficient level, we can reduce the impurities by doing more vacuum and in this way, we think that we can produce better quality thin films.

\subsection{Morphological analysis by AFM}

Figure 3 presents the AFM image of the $\mathrm{GaN} / \mathrm{Al}_{2} \mathrm{O}_{3}$ thin films for various RF powers. We obtained the highest average absolute slope $(\Delta a)$ to be $6.01^{\circ}$ at a $100 \mathrm{~W}$ RF power from AFM measurements. The lowest average absolute slope was $0.62^{\circ}$ at a $75 \mathrm{~W}$ RF power. The maximum depth $\left(R_{\mathrm{V}}\right)$ of the $\mathrm{GaN} / \mathrm{Al}_{2} \mathrm{O}_{3}$ thin film was $0.27 \mathrm{~nm}$ (the lowest value, at a $125 \mathrm{~W}$ RF power). The $\mathrm{GaN} / \mathrm{Al}_{2} \mathrm{O}_{3}$ thin film's maximum depth $\left(R_{\mathrm{V}}\right)$ was $2.31 \mathrm{~nm}$ (the highest value at a $100 \mathrm{~W} \mathrm{RF}$ power). $\mathrm{GaN} / \mathrm{Al}_{2} \mathrm{O}_{3}$ thin film's maximum height was $2.53 \mathrm{~nm}$ (the highest value at a $100 \mathrm{~W} \mathrm{RF}$ power). The maximum height of $\mathrm{GaN} / \mathrm{Al}_{2} \mathrm{O}_{3}$ was $0.44 \mathrm{~nm}$ (the lowest value, at a $125 \mathrm{~W}$ RF power). Table 4 gives the morphological parameters of $\mathrm{GaN} / \mathrm{Al}_{2} \mathrm{O}_{3}$ thin films for different RF powers. The results of the AFM analysis allow us to make many significant inferences. An increased RF power from 50 to $75 \mathrm{~W}$ caused a smoother surface by $0.26 \mathrm{~nm}$. On the other hand, the increased RF power from 75 to $100 \mathrm{~W}$ resulted in a rougher surface by $0.58 \mathrm{~nm}$. The increased RF power from 100 to $125 \mathrm{~W}$ led to a smoother surface by $0.69 \mathrm{~nm}$. As a factor that may cause surface roughness of the GaN thin film, 


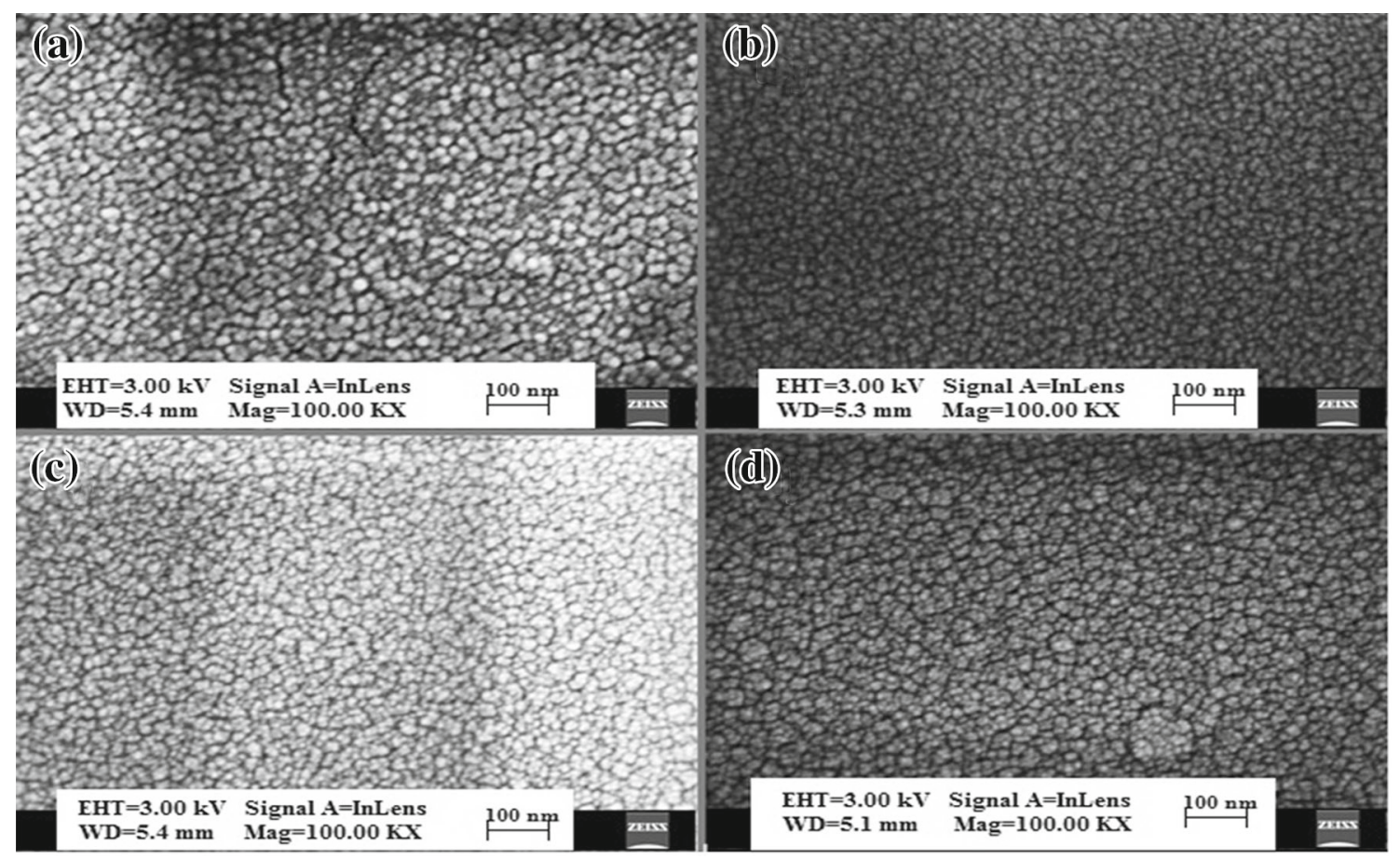

Figure 4. $\mathrm{SEM}$ image of $\mathrm{GaN} / \mathrm{Al}_{2} \mathrm{O}_{3}$ thin films with a magnification of $100.000 \mathrm{k}$ for (a) 50, (b) 75, (c) 100 and (d) $125 \mathrm{~W}$ RF powers.

Ehrlich-Schwöbel energy barriers at the step-edges induce surface features such as Hillock's step meandering, which might introduce roughness in the GaN thin film surface [56]. An almost homogeneous, nanostructured, low-rough surface of the GaN thin film was observed from AFM images. We evaluated that some little bump from XRD could correspond to the textured sample of the GaN thin film. Literature studies [57] show that the average roughness of the GaN thin films ranged from 0.7 to $20 \mathrm{~nm}$. The average roughness of our $\mathrm{GaN}$ thin films ranged from 0.09 to $0.78 \mathrm{~nm}$, being a higher value than that in the literature to some degree. The highest average roughness was $0.78 \mathrm{~nm}$ corresponding to the $100 \mathrm{~W} R F$ power growth condition, whereas the lowest average roughness was $0.09 \mathrm{~nm}$ corresponding to the $125 \mathrm{~W}$ RF power growth condition. Thereby, it was concluded that morphologically desirable $\mathrm{GaN}$ thin films were grown under $125 \mathrm{~W}$ RF power growth conditions as a result of the lowest roughness. Increasing the RF power from 50 to $75 \mathrm{~W}$ gave rise to a slight decrease in the average roughness of the thin film, resulting in a slight improvement in the surface morphology of the thin film. However, increasing the RF power from 75 to $100 \mathrm{~W}$ gave rise to an increase in the average roughness of the thin film, resulting in deterioration in the surface morphology of the thin film. Increasing the RF power from 100 to $125 \mathrm{~W}$ gave rise to a decrease in the average roughness of the thin film, resulting in an improvement in the surface morphology of the thin film. The thin films having a low roughness for optoelectronic device applications have been often preferred because it affects another layer or ohmic contact that is grown on the roughened surface. It has been shown that increasing the roughness of the interface for the $\mathrm{AlGaN} / \mathrm{GaN}$ hetero-structure leads to a reduction in the mobility and that the interface roughness effect on the electrical properties of the device has been studied in the literature [58]. In contrast, it has been found that the rough surface has contributed to the improvement in light extraction of the thin film LED because of the increased light extraction ability of the micro-rough surface which implies the effect of roughness on the optical properties of the material in the literature [59]. In another study [60], nitridation of the $\mathrm{GaN} / \mathrm{Al}_{2} \mathrm{O}_{3}$ thin film was used to reduce the surface roughness and a better PL spectrum was obtained, meaning that the optical properties of the thin film was improved by reducing the surface roughness. It should be noted that when you choose a rougher or a smoother thin film surface it is important to decide which device you prefer and the features of the device. The AFM images presented the periodic grain arrangements with almost homogeneous, nanostructured GaN thin film surfaces. The XRD measurement result proved the structure of the hexagonal GaN films and the AFM result agrees with the XRD result. For future work it is believed that thin films with better properties of the surface morphology could be achieved by optimizing other growth parameters in addition to RF power and thus more efficient optoelectronic devices can be produced.

\subsection{Morphological analysis by SEM}

Before taking SEM measurements, the GaN thin film was covered with $5 \mathrm{~nm}$ of gold under vacuum due to which excess electrons are prevented from accumulating on the surface of 
the thin film. Moreover, the conductivity of gold can provide us with a better SEM image. The secondary electron method was used to investigate the surface morphological properties of the GaN thin film. The SEM images of the GaN/ $/ \mathrm{Al}_{2} \mathrm{O}_{3}$ thin film were obtained with a magnification of $100.00 \mathrm{kX}$. The SEM images of $\mathrm{GaN} / \mathrm{Al}_{2} \mathrm{O}_{3}$ under various $\mathrm{RF}$ powers are presented in figure 4 . The dislocations are clearly visible in the thin film under $50 \mathrm{~W}$ RF power growth conditions. This result is compatible with the XRD results because the crystal quality from the XRD results was relatively poor in the case of $50 \mathrm{~W}$ growth conditions. Dislocations can increase the possibility of fragility in these regions. Dislocations in optoelectronic devices play an important role in device efficiency. It was reported that threading dislocations in the $\mathrm{p}-\mathrm{GaN}$ cap layer result in the performance of the InGaN/GaN solar cell devices to deteriorate [61]. Another study reported that dislocations can contribute to the relaxation of InGaN/GaN quantum dots [62]. It has been thought that PL imaging, cathodoluminescence mapping techniques, may be a useful method for a detailed analysis of these dislocations, but it is beyond our work and is recommended to other scientists. From SEM images it can be observed that by increasing the RF power value from 50 to $75 \mathrm{~W}$ an improvement in the GaN thin film surface was obtained. Increasing from 75 to $100 \mathrm{~W}$ also leads to an improvement in the surface of the $\mathrm{GaN}$ thin film. The best surface morphology of the $\mathrm{GaN} / \mathrm{Al}_{2} \mathrm{O}_{3}$ thin film among other RF power values was obtained at $100 \mathrm{~W}$ RF power. This result has been in agreement with both XRD and AFM results. When the RF power reached $125 \mathrm{~W}$, the surface of the $\mathrm{GaN} / \mathrm{Al}_{2} \mathrm{O}_{3}$ thin film was seen to be agglomerated to some degree. This agglomeration could be attributed to Van der Waals forces between particles [63]. Literature studies show that some properties of the thin film may change due to agglomeration on the surface. It was shown that indium aggregation in the $\mathrm{InGaN} / \mathrm{GaN}$ multiple quantum wells results in InGaN mounds, forming localized states for trapping carrier. Therefore, increased indium aggregation could improve the luminescence efficiency [64]. The granular and periodic structural surface morphology of GaN thin films was observed under all RF power growth conditions. It has also been observed that the surface of $\mathrm{GaN}$ thin films was almost homogeneous. It was concluded that the SEM images has supported the fact that the grain sizes of thin films varied with various RF powers.

\subsection{Optical analysis}

3.4a Determination of optical band gap energy by UV/Vis/ NIR: The optical band gap energy $\left(E_{\mathrm{g}}\right)$ of a material is well known as the difference between the highest point of the valence band and the lowest point of the conduction band. Some physical properties of the material being important for optoelectronic devices can be controlled by changing the optical band gap energy. The optical band gap of GaN thin

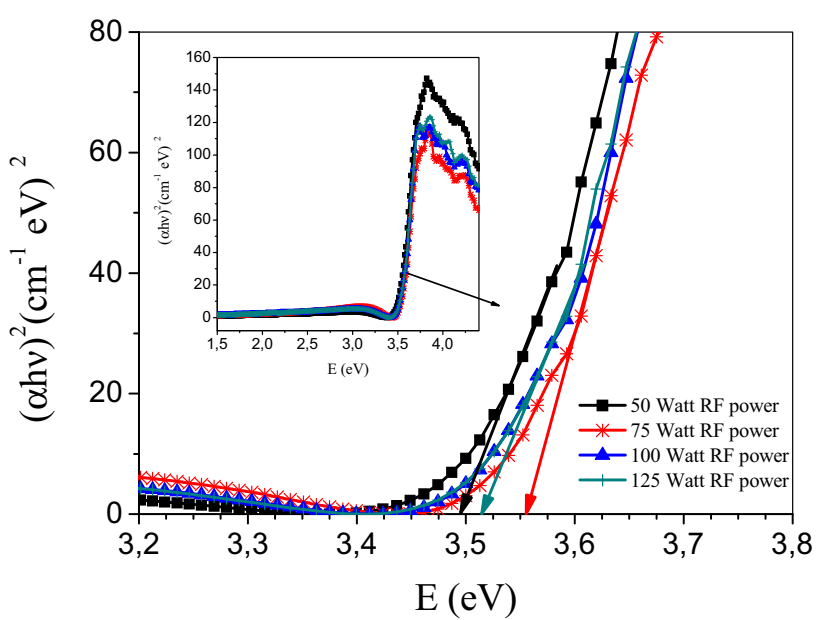

Figure 5. $(\alpha h v)^{2}$ plot $v s$. photon energy $(E)$ of $\mathrm{GaN} / \mathrm{Al}_{2} \mathrm{O}_{3}$ for various RF powers.

Table 5. Optical band gap energy of $\mathrm{GaN} /$ sapphire thin films for various RF powers.

\begin{tabular}{rc} 
Applied RF power $(\mathrm{W})$ & Optical band gap energy $(\mathrm{eV})$ \\
\hline 50 & 3.4952 \\
75 & 3.5553 \\
100 & 3.5146 \\
125 & 3.5146 \\
\hline
\end{tabular}

films was calculated by the well-known Tauc formula $[65,66]$ :

$$
(\alpha h v)^{n}=C\left(h v-E_{\mathrm{g}}\right)
$$

where $n$ is the band gap type, $C$ is the constant, $h v$ is the photon energy and $E_{\mathrm{g}}$ is the optical band gap energy of the $\mathrm{GaN}$ thin film. For the setting $n=1 / 2, E_{\mathrm{g}}$ shows the direct-allowed band gap. The absorbance $v s$. wavelength $(\mathrm{nm})$ graph was obtained by using a UV/Vis/NIR spectrophotometer. Figure 5 shows $(\alpha h v)^{2}$ vs. photon energy $(E)$ of the $\mathrm{GaN} / \mathrm{Al}_{2} \mathrm{O}_{3}$ for various RF power values. By setting $(\alpha h v)^{2}=0$ for the linear region, linear lines were correctly plotted to have the optical band gap of GaN thin films. The optical band gap energies $\left(E_{\mathrm{g}}\right)$ of the GaN thin film were $3.4952,3.5553,3.5146$ and $3.5146 \mathrm{eV}$ for $50,75,100$ and $125 \mathrm{~W}$, respectively (shown in table 5). It was understood that increasing RF power from 50 to $75 \mathrm{~W}$ led to an increase in the optical band gap energy of the thin film. This increase can be attributed to the presence of defects, leading to a change in the optical band gap of the GaN thin film. Specifically, these defects may be nitrogen $(\mathrm{N})$ vacancy defects, which caused an increase in the optical band gap of GaN thin films [67]. It should be noted that such defects can be reduced to some extent by annealing the grown thin film. We think that deep level transient and optical spectroscopy could be used to understand these defects in detail, and such studies are 


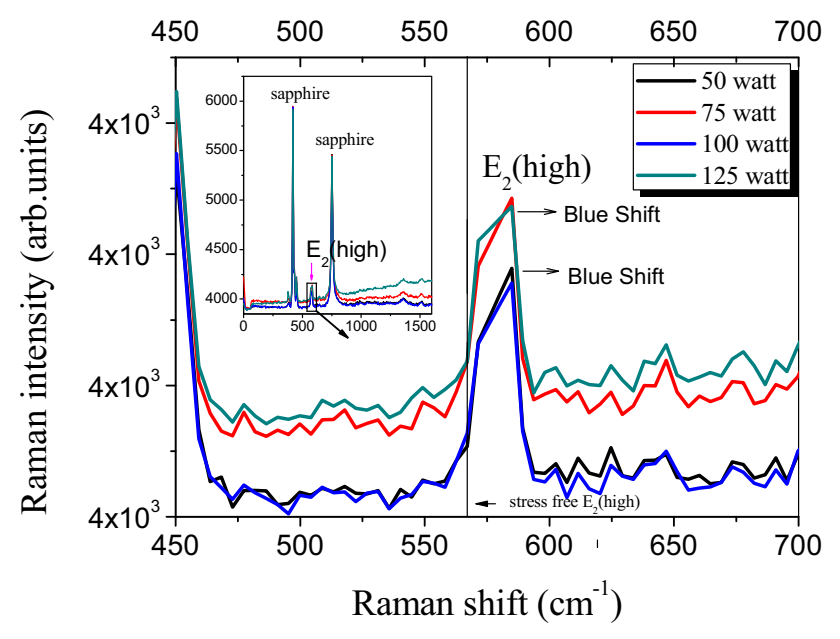

Figure 6. Raman pattern of $\mathrm{GaN} / \mathrm{Al}_{2} \mathrm{O}_{3}$ thin films for different RF powers.

suggested for future researchers. It was found that increasing the RF power from 75 to $100 \mathrm{~W}$ led to a decrease in the optical band gap energy of the GaN thin film. This could be attributed to unintentional impurities in the thin film. These could result in deep levels in the forbidden band; in this way, it reduces the optical band gap energy of thin films [68]. It was obtained that increasing RF power from 100 to $125 \mathrm{~W}$ did not lead to any changes in the optical band gap energy of the thin film. We obtained the nearest optical band gap energy as $3.4952 \mathrm{eV}$ corresponding to the $50 \mathrm{~W}$ RF power growth condition among all optical band gap values when compared to that of the known $\mathrm{GaN}$ thin film (with $3.4 \mathrm{eV}$ ). It was higher than the literature value [69]. Other optical band gap energies of the GaN thin film were also higher than those from studies in the literature [70-72]. As a result, the change in the RF power changed the optical band gap of the thin film, which can contribute to the efficiency of photonic devices such as multiple quantum well solar cells [73] and LEDs [74].

3.4b Determination of optical phonon modes and residual stress by micro-Raman: $\mathrm{GaN}$ with a hexagonal crystal structure has been a stable state and it belongs to the $C_{6 \mathrm{v}}^{4}$ space group. According to group theory, hexagonal $\mathrm{GaN}$ possesses six Raman active modes, which are $1 E_{1}(\mathrm{TO})+1 E_{1}(\mathrm{LO})+$ $2 E_{2}+1 A_{1}(\mathrm{TO})+1 A_{1}(\mathrm{LO})$. Raman patterns of $\mathrm{GaN} / \mathrm{Al}_{2} \mathrm{O}_{3}$ thin films for various RF powers are presented in figure 6 . We observed very strong peaks at 418.55 and $752.23 \mathrm{~cm}^{-1}$ belonging to $A_{1 \mathrm{~g}}$ and $E_{1 \mathrm{~g}}$ modes of the sapphire substrate, respectively ( $A$ shows that wave functions are singly degenerate, $E$ shows wave functions are doubly or triply degenerate, $g$ shows an even wave function). These peaks are very compatible with the literature study [75]. The peak at $584.82933 \mathrm{~cm}^{-1}$ was detected under all RF power growth conditions. It has been attributed to the vibration of $E_{2}$ (high) [76] and it has been supported with a previous study [77]. From Raman measurements, we have found that the highest Raman intensity corresponds to the $75 \mathrm{~W}$ RF power growth. In contrast, we have found that the lowest Raman intensity corresponds to $100 \mathrm{~W}$ RF power growth conditions, as clearly shown in figure 6. This higher Raman intensity could be attributed to the surface states and plasmon-phonon coupling effects $[78,79]$. The mechanical properties of the thin films have a significant effect on some properties, such as the fragility of the material, and the investigation and control of these properties becomes particularly important in device applications. The residual stress in the $\mathrm{GaN}$ thin film can be computed using the shift in $E_{2}$ (high) optical phonon mode from Raman measurements. A stress free Raman shift of $E_{2}$ (high) optical phonon vibration of the $\mathrm{GaN}$ thin film was reported to be $567.2 \mathrm{~cm}^{-1}$ [80,81]. If the Raman shift of the GaN thin film of $E_{2}$ (high) optical phonon vibration is higher than the stress free value (higher wavenumber), it is called blue shift. In this case, the thin film has a compressive stress. In contrast, if the Raman shifts of the GaN thin film of $E_{2}$ (high) optical phonon vibration falls below the stress free value (it is in the lower wavenumber), it is called red shift. This implies that the GaN thin film has tensile stress. Residual stresses in $\mathrm{GaN}$ thin films were successfully obtained from the following equation (9):

$$
\sigma=\Delta w / k
$$

$\sigma$ shows the residual stress, $\Delta w$ shows the shift of the $E_{2}$ (high) peak and $k=4.3 \mathrm{~cm}^{-1}(\mathrm{GPa})^{-1}$ shows the Raman stress coefficient. In the obtained thin films under all RF power growth conditions, it was observed that the Raman shift of the GaN thin film of $E_{2}$ (high) optical phonon vibration is in the blue region, indicating that the thin film has compressive stress. The residual stress in the GaN thin film was achieved to be $4.0998 \mathrm{GPa}$ under 50, 75, 100 and $125 \mathrm{~W}$ RF power growth conditions. From the XRD results, the in-plane stress in the GaN thin film was obtained to be $3.9984 \mathrm{GPa}$ and the stress type of the material was found to be compressive stress. When the results of Raman and XRD were compared, it was found that the stress values were close to each other and showed consistent results. We can make the following evaluations when we analyse the causes of this stress in the $\mathrm{GaN}$ thin film. The sapphire has a hexagonal structure with the $(c)$ plane (0001) orientation and the lattice constants of sapphire have a single crystal structure with $a=4.758 \AA$ and $c=12.992 \AA$. The lattice parameters of $\mathrm{GaN}$ thin films obtained from the XRD results are smaller than the lattice parameters of the substrate. In this case, since the GaN thin film has a small lattice constant relative to the substrate as it grows, it will compress the substrate lattice parameter to its size. This will cause compressive stress to occur. Another factor that allows compressive stress to form in $\mathrm{GaN}$ thin films is the difference between thermal expansion coefficients. The thermal expansion coefficients of $\mathrm{GaN}$ and sapphire are $\alpha_{\mathrm{GaN}}=$ $5.6 \times 10^{-6} \mathrm{~K}^{-1}$ and $\alpha_{\text {sapphire }}=9.0 \times 10^{-6} \mathrm{~K}^{-1}$, respectively. 
Thin films were grown at a substrate temperature of $300^{\circ} \mathrm{C}$. At this stage, the thin films are expanding in the ratio of thermal expansion coefficients since thermal constants of them are different, when the films are cooled down, compressive stress is generated in the thin films. As a result, it was evaluated that the residual stress in GaN thin films originated from two factors, internal stress (lattice parameter difference) and thermal stress (thermal coefficient difference). These evaluations have been seen to be fully supported by the literature studies [82-84]. Beyond our work, there are many stress models in the studies that are reported, and they explain in detail the possible causes of stress in thin films [85-87]. In conclusion, controlling and analysis of residual stress in GaN thin films, being one of the mechanical properties of $\mathrm{GaN}$ thin films, is of paramount importance for device application since tensile stress causes cracking in the device and problems of limitation of the sheet usable thickness [88]. On the other hand, compressive stress causes buckling and a separation layer in the device [89], leading to short circuit problems in the device. From all of the measurements, it was inferred that the morphological, optical and structural properties of the GaN thin film could be changed by changing the RF power. This could contribute to the development of better quality GaN-based optoelectronic devices.

\section{Conclusions}

GaN thin films with a polycrystalline hexagonal structure were successfully grown on a $\mathrm{Al}_{2} \mathrm{O}_{3}$ substrate using $\mathrm{RF}$ magnetron sputtering. The best and the worst crystallization in the structure of the $\mathrm{GaN} / \mathrm{Al}_{2} \mathrm{O}_{3}$ thin film were achieved under 100 and $125 \mathrm{~W}$ RF power growth conditions, respectively, meaning that the optimum value for growing our thin film was $100 \mathrm{~W}$ among the applied RF power values. Increased RF power from 50 to $75 \mathrm{~W}$ gives rise to an increment in the optical band gap of the thin film due to the presence of defects, which is called as $\mathrm{N}$ vacancy defects. On the other hand, increased RF power from 75 to $100 \mathrm{~W}$ led to a decrease in the optical band gap of our thin film because of the deep level defect which explained that $\mathrm{Ga}$ and $\mathrm{N}$ could be from the decomposition of $\mathrm{GaN}$, due to which unintentional impurities could form in the thin film. The AFM images presented periodic grain arrangements with almost homogeneous, nanostructured GaN thin film surfaces. From SEM analysis, it was found that the best surface morphology of the $\mathrm{GaN} / \mathrm{Al}_{2} \mathrm{O}_{3}$ thin film was obtained under $100 \mathrm{~W}$ RF conditions among other RF power values. This result has been consistent with both XRD and AFM results. Under $125 \mathrm{~W}$ RF power conditions, the surface of the $\mathrm{GaN} / \mathrm{Al}_{2} \mathrm{O}_{3}$ thin film was seen to be agglomerated; this could be attributed to the Van der Waals force between the particles. The Raman results showed a characteristic $E_{2}$ (high) optical phonon mode of hexagonal GaN. The residual stress in the $\mathrm{GaN}$ thin film was achieved to be $4.0998 \mathrm{GPa}$ under all RF power growth conditions. From the XRD results, the stress in the GaN thin film was obtained to be $3.9984 \mathrm{GPa}$ and the stress type of the material was found to be compressive stress. When the results of Raman and XRD were compared, it was found that the stress values were close to each other and showed consistent results. It was concluded that the residual stress in $\mathrm{GaN}$ thin films originated from two factors: internal stress (lattice parameter difference) and thermal stress (thermal coefficient difference). In brief, we evaluate that it is possible to control the morphological, optical and structural properties of the $\mathrm{GaN}$ thin film to some degrees by changing the RF power. Therefore, it could grow as better quality GaN thin films to be used in optoelectronic device applications. In the long view, we think that scientists can produce more efficient $\mathrm{GaN}$-based devices by optimizing the $\mathrm{GaN}$ thin film growth conditions.

\section{Acknowledgements}

This work was supported by Muş Alparslan University Scientific Research Coordination Unit. Project Number: BAP18FEF-4901-03.

\section{References}

[1] Strite S and Morkoc H 1992 J. Vac. Sci. Technol. B B10 1237

[2] Neumayer D A and Ekerdt J G 1996 Chem. Mater. 89

[3] Hu J, Zhang Y, Sun M, Piedra D, Chowdhury N and Palacios T 2018 Mater. Sci. Semicond. Process. 7875

[4] Nouri N and Rashedi G 2017 Phys. E Low Dimens. Syst. Nanostruct. 85324

[5] Pampili P and Parbrook P J 2017 Mater. Sci. Semicond. Process. 62180

[6] Chatterjee U, Park J-H, Um D-Y and Lee C-R 2017 Renewable Sustainable Energy Rev. 791002

[7] Mantarcı A and Kundakçi M 2019 Opt. Quant. Electron. 51 81

[8] King S W, Davis R F and Nemanich R J 2014 J. Vac. Sci. Technol. A: Vac. Surf. Films 32061504

[9] Doan T C, Li J, Lin J Y and Jiang H X 2016 AIP Adv. 6075213

[10] Mohanty G and Sahoo B K 2016 Superlattices Microstruct. 93 226

[11] Brendel M, Pertzsch E, Abrosimova V, Trenkler T and Weyers M 2016 in III-Nitride ultraviolet emitters: technology and applications M Kneissl and J Rass (eds) (Cham: Springer International Publishing) p 219

[12] Hu X-L, Wen R-L, Qi Z-Y and Wang H 2018 Mater. Sci. Semicond. Process. 7961

[13] Moon W H, Kim H J and Choi C H 2007 Scr. Mater. 56345

[14] He X G, Zhao D G, Jiang D S, Zhu J J, Chen P, Liu Z S et al 2016 J. Alloys Compd. 66216

[15] Saito W, Suwa T, Uchihara T, Naka T and Kobayashi T 2015 Microelectron. Reliab. 551682

[16] Lee J-M, Min B-G, Ju C-W, Ahn H-K and Lim J-W 2017 Curr. Appl. Phys. 17157

[17] Qian H, Lee K B, Vajargah S H, Novikov S V, Guiney I, Zaidi Z H et al 2017 J. Cryst. Growth 459185 
[18] Martinez-Guerrero E, Adelmann C, Chabuel F, Simon J, Pelekanos N T, Mula G et al 2000 Appl. Phys. Lett. 77809

[19] Xing Z, Wang R X, Fan Y M, Wang J F, Zhang B S and Xu K 2017 Mater. Sci. Semicond. Process. 57132

[20] Liu Z, Chong W C, Wong K M and Lau K M 2015 Microelectron. Eng. 14898

[21] Lin J-H, Huang S-J, Su Y-K and Huang K-W 2015 Appl. Surf. Sci. 354168

[22] Mantarc1 A and Gündüz B 2016 Opt. Quant. Electron. 48547

[23] Miyoshi M, Tsutsumi T, Kabata T, Mori T and Egawa T 2017 Solid State Electron. 12929

[24] Sheu J-K, Chen P-C, Shin C-L, Lee M-L, Liao P-H and Lai W-C 2016 Sol. Energy Mater. Sol. Cells 157727

[25] Dong Y, Son D-H, Dai Q, Lee J-H, Won C-H, Kim J-G et al 2018 Sens. Actuators B Chem. 260134

[26] Khan M R, Smith J R, Tompkins R P, Kelley S, Litz M, Russo $\mathrm{J}$ et al 2017 Solid State Electron. 13624

[27] Kawwam M and Lebbou K 2014 Appl. Surf. Sci. 292906

[28] Braniste T, Ciers J, Monaico E, Martin D, Carlin J F, Ursaki V V et al 2017 Superlattices Microstruct. 102221

[29] Gu S, Chagarov E A, Min J, Madisetti S, Novak S, Oktyabrsky S et al 2014 Appl. Surf. Sci. 3171022

[30] Wang M, Bian J, Sun H, Liu W, Zhang Y and Luo Y 2016 Appl. Surf. Sci. 389199

[31] Mutlu K, Asim M and Erman E 2017 Mater. Res. Express 4 016410

[32] Erdoğan E, Kundakçı M and Mantarcı A 2016 J. Phys.: Conf. Ser.: IOP Publishing 707012019

[33] Mantarcı A and Kundakçı M 2017 AIP Conf. Proc. 1833 020119

[34] Fong C Y, Ng S S, Yam F K, Abu Hassan H and Hassan Z 2015 Vacuum 119119

[35] Yin M L, Zou C W, Li M, Liu C S, Guo L P and Fu D J 2007 Nucl. Instrum. Methods Phys. Res. B 262189

[36] Li L, Huang J, Yang W, Tang K, Ren B, Xu H et al 2016 Surf. Coat. Technol. 3071024

[37] Wu Y, Xue C, Zhuang H, Tian D, Ya L, He J et al 2006 J. Cryst. Growth 292294

[38] Kuo D-H, Tuan T T A, Li C-C and Yen W-C 2015 Mater. Sci. Eng. B 19313

[39] Li S, Fang G, Long H, Wang H, Huang H, Mo X et al 2012 J. Lumin. 1321642

[40] Abud S H, Selman A M and Hassan Z 2016 Superlattices Microstruct. 97586

[41] Yudate S, Fujii T and Shirakata S 2008 Thin Solid Films 517 1453

[42] Kusaka K, Hanabusa T and Tominaga K 2004 Vacuum 74 613

[43] Shinoda H and Mutsukura N 2008 Thin Solid Films 5162837

[44] Coutts T J 1992 Int. J. Sol. Energy 12223

[45] Selman A M, Hassan Z and Husham M 2014 Measurement 56 155

[46] Schwaiger S, Argut I, Wunderer T, Rösch R, Lipski F, Biskupek J et al 2010 Appl. Phys. Lett. 96231905

[47] Patterson A L 1939 Phys. Rev. 56978

[48] Hughes W C, Rowland Jr. W H, Johnson M A L, Fujita S, Cook Jr. J W, Schetzina J F et al 1995 J. Vac. Sci. Technol. B Microelectron. Nanometer Struct. Process. Meas. Phenom. 13 1571

[49] Hwang D-K, Bang K-H, Jeong M-C and Myoung J-M 2003 J. Cryst. Growth 254449
[50] Bragg W H and Bragg W L 1913 Proc. R. Soc. London, Ser. A 88428

[51] Aggarwal N, Krishna S T C, Goswami L, Mishra M, Gupta G, Maurya K K et al 2015 Cryst. Growth Des. 152144

[52] Liu L and Edgar J H 2002 Mater. Sci. Eng. R Rep. 3761

[53] Kisielowski C, Krüger J, Ruvimov S, Suski T, Ager J W, Jones E et al 1996 Phys. Rev. B 5417745

[54] Kozawa T, Kachi T, Kano H, Nagase H, Koide N and Manabe K 1995 J. Appl. Phys. 774389

[55] Van de Walle C G 2003 Phys. Rev. B 68165209

[56] Kaufmann N A, Lahourcade L, Hourahine B, Martin D and Grandjean N 2016 J. Cryst. Growth 43336

[57] Kim H W and Kim N H 2004 Appl. Surf. Sci. 236192

[58] Demir M, Yarar Z and Ozdemir M 2013 Solid State Commun. 15829

[59] Li J-S, Tang Y, Li Z-T, Ding X-R and Li Z 2017 Appl. Surf. Sci. 41060

[60] Kum D and Byun D 1997 J. Electron. Mater. 261098

[61] Zhang Y, Kappers M J, Zhu D, Oehler F, Gao F and Humphreys C J 2013 Sol. Energy Mater. Sol. Cells 117279

[62] Yang D, Wang L, Hao Z-B, Luo Y, Sun C, Han Y et al 2016 Superlattices Microstruct. 99221

[63] Kudrawiec R, Nyk M, Syperek M, Podhorodecki A, Misiewicz J and Strek W 2006 Appl. Phys. Lett. 88181916

[64] You Y-S, Feng S-W, Wang H-C, Song J and Han J 2017 J. Lumin. 182196

[65] Tauc J and Menth A 1972 J. Non-Cryst. Solids 8569

[66] Stenzel O 2005 The physics of thin film optical spectra (Berlin, Heidelberg: Springer)

[67] Li J, Liu H and Wu L 2018 Opt.-Int. J. Light Electron Opt. 154 378

[68] Cui Z, Ke X, Li E and Liu T 2016 Mater. Des. 96409

[69] Yang M, Chang B, Hao G, Wang H and Wang M 2015 Opt.-Int. J. Light Electron Opt. 1263357

[70] Said A, Debbichi M and Said M 2016 Opt.-Int. J. Light Electron Opt. 1279212

[71] Gueddim A, Eloud T, Messikine N and Bouarissa N 2015 Superlattices Microstruct. 77124

[72] Liao J-H, Huang H-W, Cheng L-C, Liu H-H, Chyi J-I, Cai D-P et al 2015 Sol. Energy Mater. Sol. Cells 132544

[73] Liu S, Wang Q, Xiao H, Wang K, Wang C, Wang X et al 2017 Superlattices Microstruct. 109194

[74] Zhang H, Zhang D and Wang W 2017 J. Lumin. 192470

[75] Hushur A, Manghnani M H and Narayan J 2009 J. Appl. Phys. 106054317

[76] Harima H 2002 J. Phys.: Condens. Matter 14 R967

[77] Chen P, Zhang R, Zhao Z, Xi D, Shen B, Chen Z et al $2001 \mathrm{~J}$. Cryst. Growth 225150

[78] Sekine T, Komatsu Y, Iwaya R, Kuroe H, Kikuchi A and Kishino K 2017 J. Phys. Soc. Jpn. 86074602

[79] Dyson A 2009 J. Phys.: Condens. Matter 21174204

[80] Nootz G, Schulte A, Chernyak L, Osinsky A, Jasinski J, Benamara M et al 2002 Appl. Phys. Lett. 801355

[81] Park B-G, Saravana Kumar R, Moon M-L, Kim M-D, Kang T-W, Yang W-C et al 2015 J. Cryst. Growth 425149

[82] Spaepen F 2000 Acta Mater. 4831

[83] Chen K-S, Zhang X and Lin S-Y 2003 Thin Solid Films 434 190

[84] Köstenbauer H, Fontalvo G A, Keckes J and Mitterer C 2008 Thin Solid Films $\mathbf{5 1 6} 1920$

[85] Thornton J A and Hoffman D W 1989 Thin Solid Films 1715 
[86] Barghout K and Chaudhuri J 2004 J. Mater. Sci. 39 5817

[87] Öztürk M K, Altuntaş H, Çörekçi S, Hongbo Y, Özçelik S and Özbay E 2011 Strain 4719
[88] Mizushima I, Tang P T, Hansen H N and Somers M A J 2006 Electrochim. Acta $\mathbf{5 1} 6128$

[89] Moon M W, Chung J W, Lee K R, Oh K H, Wang R and Evans A G 2002 Acta Mater. 501219 